\title{
Galactosemia, a Single Gene Disorder With Epigenetic Consequences
}

\author{
DAVID J. COMAN, DAVID W. MURRAY, JENNIFER C. BYRNE, PAULINE M. RUDD, PAOLA M. BAGAGLIA, \\ PETER D. DORAN, AND EILEEN P. TREACY
}

\begin{abstract}
National Centre for Inherited Metabolic Disorders [D.J.C., E.P.T.], Children's University Hospital, Dublin 1, Ireland; UCD School of Medicine and Medical Sciences [D.W.D., P.M.B.], Mater Misericordiae University Hospital, Dublin 7, Ireland; The National Institute for Bioprocessing Research and Training (NIBRT) [J.C.B., P.M.R.], University College, Dublin 4, Ireland; School of Medicine [D.J.C.], University of Queensland, Brisbane, 4072 Australia
\end{abstract}

\begin{abstract}
Long-term outcomes of classic galactosemia (GAL) remain disappointing. It is unclear if the complications result mainly from prenatal-neonatal toxicity or persistent glycoprotein and glycolipid synthesis abnormalities. We performed gene expression profiling ( $\mathrm{T}$ transcriptome) to characterize key-altered genes and gene clusters of four patients with GAL with variable outcomes maintained on a galactose-restricted diet, compared with controls. Significant perturbations of multiple cell signaling pathways were observed including mitogen-activated protein kinase (MAPK) signaling, regulation of the actin cytoskeleton, focal adhesion, and ubiquitin mediated proteolysis. A number of genes significantly altered were further investigated in the GAL cohort including SPARC (osteonectin) and S100A8 (S100 calcium-binding protein). The whole serum $\mathrm{N}$-glycan profile and $\mathrm{IgG}$ glycosylation status of 10 treated patients with GAL were compared with healthy control serum and $\mathrm{IgG}$ using a quantitative high-throughput analytical HPLC platform. Increased levels of agalactosylated and monogalactosylated structures and decreases in certain digalactosylated structures were identified in the patients. The persistent abnormal glycosylation of serum glycoproteins seen with the microarray data indicates persisting metabolic dyshomeostasis and gene dysregulation in "treated" GAL. Strict restriction of dietary galactose is clearly life saving in the neonatal period; long-term severe galactose restriction may contribute to ongoing systemic abnormalities. (Pediatr Res 67: 286-292, 2010)
\end{abstract}

$\mathrm{G}$ alactosemia (GAL) (McKusick 230400) caused by deficiency of galactose-1-phosphate uridyltransferase (GALT: EC 2.7.712) is associated with an impaired ability to metabolize galactose, derived from dietary lactose and endogenous sources (1). Galactose is normally converted to glucose1-phosphate and metabolized to release energy or alternatively galactose may be metabolized to UDP-galactose (UDP-GAL) and its derivatives, which serve as key substrate donors for the biosynthesis of glycoproteins and glycolipids.

The acute symptoms of GAL include poor feeding, vomiting, liver dysfunction, hypotonia and lethargy, cataracts, and predisposition to sepsis. Long-term treatment, consisting of a severe restriction of dietary galactose is life saving in the newborn and avoids often fatal liver disease. However, long-

Received August 7, 2009; accepted November 7, 2009.

Correspondence: Eileen P. Treacy, M.D., National Centre for Inherited Metabolic Disorders, Children's University Hospital, Temple Street, Dublin 1, Ireland; e-mail: eileen.treacy@cuh.ie

Supported by the Irish Galactosemia Society. term follow-up has shown that, despite a strict diet, most patients develop abnormalities such as intellectaul, motor and language development and hypergonadotrophic hypogonadism in females (1-4).

GAL when untreated is thought to simulate a number of the inherited genetic defects of $\mathrm{N}$-glycosylation as there are apparent abnormalities noted in glycosylation of a number of glycoproteins such as transferrin and FSH in affected females (1,5-7). Untreated patients with GAL have been shown to have truncated glycans deficient in sialic acid and galactose suggesting defective $N$-glycan assembly and processing $(7,8)$.

There are a number of possible pathophysiological mechanisms for the complications of treated GAL. GALT deficiency may lead to defective synthesis of glycoproteins and galactolipids critical for normal myelin formation possibly as a result of defective transfer of galactose from UDP-GAL and low UDP-Gal concentrations. Galactose-1-phosphate also competitively inhibits UDP-glucose pyrophosphorylase leading to a reduction in UDP-glucose/galactose content in GALTdeficient cells (9). GALT-deficient fibroblasts responded to galactose challenge by up-regulating a set of genes characteristic of endoplasmic reticulum (ER) shock and unfolded protein response (10) Deficiencies of glucose/galactose, crucial glycosyl donors could impair protein glycosylation reactions and trigger ER stress (10).

We recently compared outcomes in siblings with up to $25 \mathrm{y}$ of treatment from our center where there is a relatively high incidence of GAL. Outcomes were disappointing with a high incidence of decreased intelligence quotient (IQ) and neurologic complications, despite strict galactose restriction with no correlation with biochemical control (4). These findings have led us to consider that treated patients with GAL still have persistent systemic abnormalities of $\mathrm{N}$-glycosylation, which might cause abnormal glycoprotein functioning and protein folding (in the CNS and systematically).

We sought to study the contemporary gene expression analysis (microarray analysis) in a subset of our patients with GAL to include two cases with good neurologic outcomes and two with poorer outcomes to identify possible epigenetic

\footnotetext{
Abbreviations: GAL, galactosemia; KEGG, kyoto encylopaedia of genes and
} genomes; G0, agalactosylated; G1, monogalactosylated; G2, digalactosyalted 
effects determining variable outcomes. We have identified multiple aberrations in gene expression in these patients compared with controls in important cell survival pathways such as the ubiquitin-mediated proteolysis (UPR), $\mathrm{Ca}^{2+}$ signaling, RAS and mitogen-activated protein kinase (MAPK) signaling, actin cytoskeleton, glycosylation, and cell adhesion.

We have also performed biochemical analysis of current glycosylation status of $N$-linked serum glycoproteins, in two of the earlier patients and in a second cohort of adult patients with classical GAL.

\section{METHODS}

Patients with GAL. The characteristics of the four study subjects for the microarray analysis including the two who had glycoprotein analysis performed are listed in Table 1. Patients 1 and 2 display severe neurodevelopmental sequelae of GAL, whereas patients 3 and 4 display normal intellect and executive functioning. Patients 1 and 3 are siblings. Three subjects are adults of Irish origin and have severe GAL diagnosed in the neonatal period with homozygozity for the null allele $Q 188 R$. One subject is a 3-y-old African boy who has a milder variant of GAL (homozygous for $S 135 \mathrm{~L}$ ), who was late diagnosed at age two and has cognitive impairment (11). Five milliliters of whole blood was collected for lymphocyte extraction from patients and a control group.

We performed normal phase (NP) HPLC $N$-glycan analysis for two of the patients described in Table 1 as earlier, (patients 1 and 4) and a second cohort of eight patients with classic GAL, seven adults and one teenager. All are homozygous for the severe mutation $Q 188 R$ and have favorable outcomes with mean IQ scores $>80$ and remain on galactose restriction of $<150 \mathrm{mg} / \mathrm{d}$, with the exception of patient 1 with a current IQ of 40 and patient $M$ who had self liberalized his diet to $\sim 4 \mathrm{~g}$ galactose/d (approximately half of the normal adult galactose intake). Ethics approval for this study was obtained from the Ethics Committee of the Children's University Hospital, Dublin. All patients and controls gave full informed written consent before enrolment.

Microarray analysis. T lymphocytes were extracted from whole blood within $2 \mathrm{~h}$ of collection using enrichment columns (R\&D Systems). RNA was extracted and prepared according to the Affymetrix guidelines for Human Genome U133 Plus 2.0 microarrays. Microarrays were scanned using an Axon scanner with images analyzed using GenePix image software. The resulting CEL files were analyzed using RMAexpress software and genes with at least 1.5 -fold expression change $(p<0.05)$ were shortlisted for further analysis. Two comparisons were performed; expression profiles between normal and patients with GAL in addition to between patients with mild and severe GAL. Control samples were derived from three healthy adult controls. Shortlisted genes were further studied using DAVID EASE (12) (www.david.abcc.ncifcrf.gov). Genesets were curated from biochemical pathway data available from DAVID EASE and the kyoto encyclopedia of genes and genomes (KEGG) (www.genome.jp/kegg). KEGG pathways with two or more members represented in the gene lists of dysregulated genes were shortlisted.

Reverse-transcription and real-time polymerase chain reaction. To validate our microarray findings, we verified the levels of three dysregulated genes (RGS10, SPARC, and S100A) in addition to one housekeeping gene $(G A P D H)$.

Total RNA $(2 \mu \mathrm{g})$ from the patients and controls was retrotranscribed using Super Script System (Invitrogen) and quantitative real-time PCR was performed using a rotor gene system (Corbett research). For every sample, the genes were amplified in triplicate in the same run. PCR results between the four index patients and controls were compared and the results were analyzed using the $t$ test. In addition, the quantitative real time PCR experiment was independently validated from RNA samples derived from three of the second patient cohort used for the glycobiology studies.

Methods for NP HPLC glycan analysis. A high-throughput analytical platform was applied to whole serum and purified $\operatorname{IgG} N$-glycans, using previously described methods (13). This entailed sample immobilization, enzymatic $\mathrm{N}$-glycan release, fluorescent labeling with 2-aminobenzamide (2-AB), and NP HPLC profiling with database interrogation. IgGs were then isolated from patient serum and the $\mathrm{N}$-glycans were then processed and labeled with $2-\mathrm{AB}$ before injection onto the HPLC. Undigested serum $\mathrm{IgG}$ $\mathrm{N}$-glycans initially analyzed revealed differences in the G0/G1 and (G0/ G1)/G2 ratios between patient samples and a pooled control sample from $>20$ healthy individuals. The IgG-derived $N$-glycans were then digested with a Arthrobacter ureafaciens sialidase ( $\alpha 2-3,6,8$ sialic acid) (ABS) and bovine kidney $\alpha$-fucosidase $(\alpha 1-2,6,3,4)$ (BKF) to remove sialic acids and core fucose, respectively, to allow a more accurate calculation of the G0/G1 and (G0/G1)/G2 ratios.

\section{RESULTS}

Microarray analysis. Comparing the dataset of patients with GAL with controls, 9797 genes in total were up-regulated, and 9896 genes were down-regulated involving a number of major pathways. As seen in Figure 1, the four most represented pathways included the MAPK signaling pathway, regulation of actin cytoskeleton, focal adhesion, and ubiquitin mediated proteolysis.

Sixteen genes were up-regulated at least 100-fold in T lymphocytes from patients with GAL in comparison with control. The top genes up-regulated and down-regulated, respectively, are noted in Table 2. When comparing the profiles of patients with poor versus good outcomes, 212 genes were noted to be upregulated in the severe outcome group, and 232 genes were down-regulated (Table 3).

Table 1. Patient characteristics

\begin{tabular}{|c|c|c|c|c|}
\hline Patient demographics & Patient $1 *+$ & Patient 2 & Patient $3 *$ & Patient 4 \\
\hline CNS severity & Severe & Severe & Mild & Mild \\
\hline Age at time of study & 26 & 3 & 27 & 25 \\
\hline Age at diagnosis & Neonate & 1 & Neonate & Neonate \\
\hline Gender & Female & Male & Male & Female \\
\hline Nationality & Irish & Nigerian & Irish & Irish \\
\hline Genotype & Q188R/Q188R & $\mathrm{S} 135 \mathrm{~L} / \mathrm{S} 135 \mathrm{~L}$ & Q188R/Q188R & Q188R/Q188R \\
\hline GALT activity $\dagger$ & $<0.5$ & $<0.5$ & $<0.5$ & $<0.5$ \\
\hline Growth $<10$ th centile & Yes & Yes & No & No \\
\hline $\begin{array}{l}\text { Complications/ } \\
\text { outcome }\end{array}$ & $\begin{array}{l}\text { Severe developmental delay, IQ } 40 \\
\text { verbal dyspraxia, ataxia } \\
\text { hypergonadotrophic } \\
\text { hypogonadism }\end{array}$ & $\begin{array}{l}\text { Moderate-severe global developmental } \\
\text { delay, significant verbal dyspraxia. } \\
\text { Cataracts noted } 3 \text { y }\end{array}$ & Normal IQ & $\begin{array}{l}\text { Mild speech and language delay } \\
\text { as a child. Normal IQ } \\
\text { hypergonadotrophic } \\
\text { hypogonadism }\end{array}$ \\
\hline MRI CNS imaging & $\begin{array}{l}\text { Prominent cerebellar sulci, cerebral } \\
\text { atrophy }\end{array}$ & Poor and delayed myelination (1.5 y) & Normal & \\
\hline
\end{tabular}

Patients 1 and 2 display severe developmental and intellectual complications and patients 3 and 4 have normal intellectual outcomes.

* Designates siblings.

$\dagger$ GALT expressed as $\mu$ mole subc/H/gHb, galactose-1-phosphate.

\$ Mother on limited galactose intake during pregnancy. 


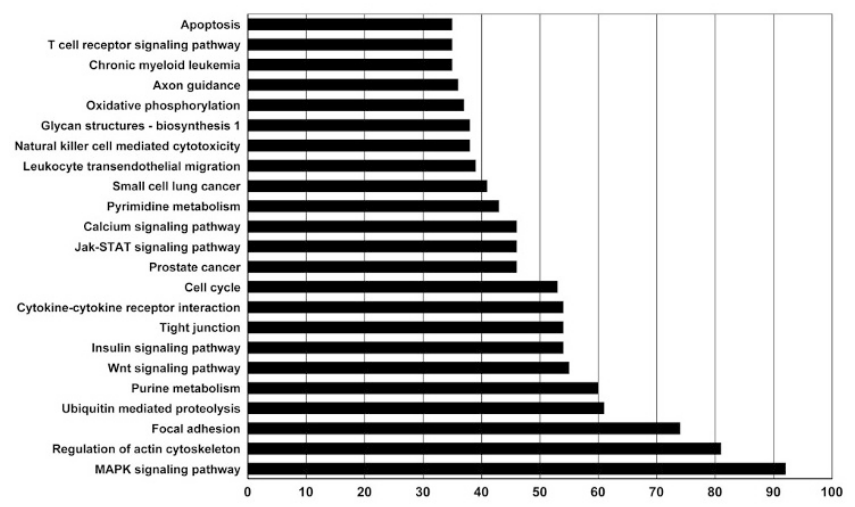

Figure 1. KEGG pathways where at least two gene members are dysregulated.

Table 2. Differential expression of genes (up-regulated/downregulated) in total group of galactosemic patients in comparison with controls

\begin{tabular}{|c|c|c|c|}
\hline NCBI number & Gene title & $\begin{array}{l}\text { Gene } \\
\text { symbol }\end{array}$ & $\begin{array}{c}\text { Fold increase/ } \\
\text { decrease }\end{array}$ \\
\hline \multicolumn{4}{|l|}{ Up-regulated } \\
\hline NM_001004 & $\begin{array}{l}\text { Ribosomal protein, } \\
\text { large P2 }\end{array}$ & RPLP2 & 324.0 \\
\hline NM_004126 & $\begin{array}{l}\text { Guanine nucleotide } \\
\text { binding }\end{array}$ & GNG11 & 205.2 \\
\hline NM_004657 & $\begin{array}{l}\text { Serum deprivation } \\
\text { response }\end{array}$ & $S D P R$ & 165.8 \\
\hline NM_002925 & $\begin{array}{l}\text { Regulator of G protein } \\
\text { signalling }\end{array}$ & $R G S 10$ & 159.1 \\
\hline NM_002213 & Integrin, beta 5 & ITGB5 & 147.3 \\
\hline NM_053031 & $\begin{array}{l}\text { Myosin light chain } \\
\text { kinase }\end{array}$ & $M Y L K$ & 146.6 \\
\hline NM_003973 & Ribosomal protein L14 & RPL14 & 139.2 \\
\hline NM_003118 & Secreted protein acidic & SPARC & 138.7 \\
\hline NM_002964 & $\begin{array}{l}\text { S100 calcium binding } \\
\text { protein }\end{array}$ & S100A8 & 122.3 \\
\hline NM_130782 & $\begin{array}{l}\text { Regulator of } \mathrm{G} \text { protein } \\
\text { signalling }\end{array}$ & $R G S 18$ & 121.7 \\
\hline \multicolumn{4}{|l|}{ Down-regulated } \\
\hline NM_004574 & Septin 4 & SEP-04 & 85.8 \\
\hline NM_024092 & $\begin{array}{l}\text { Transmembrane protein } \\
109\end{array}$ & TMEM109 & 49.2 \\
\hline NM_001037500 & Defensin, beta 124 & $D E F B 124$ & 40.7 \\
\hline NM_152603 & Zinc finger & ZNF567 & 27.1 \\
\hline NM_175066 & Dead box polypeptide & $D D X 51$ & 26.7 \\
\hline
\end{tabular}

The corresponding KEGG pathway analysis comparing poor versus favorable neurologic outcomes showed dysregulation of multiple pathways including components of the actin system, MAPK signaling, cell cycle, calcium signaling, natural killer cell-mediated cytotoxicity, cell adhesion molecules, and the hematopoietic cell lineage pathways (Fig. 2).

To confirm the gene array expression data, real-time quantitative RT-PCR was performed for three genes; SPARC, $S 100 A 8$, and RGS10 (listed in Table 2). The gene expression was independently validated in three RNA samples derived from patient with GAL samples (not used in the primary analysis). All three genes were independently confirmed to be up-regulated in GAL lymphocytes in comparison with normal (Fig. 3).

Assessment of $\mathrm{N}$-glycan galactose status. Figure 4 shows the main pools of structures present in a NP HPLC profile of
Table 3. Differential expression of genes (up-regulated/downregulated) in galactosemic patients with poor outcomes in comparison to favourable outcomes

\begin{tabular}{|c|c|c|c|}
\hline NCBI number & Gene title & $\begin{array}{l}\text { Gene } \\
\text { symbol }\end{array}$ & $\begin{array}{c}\text { Fold increase/ } \\
\text { decrease }\end{array}$ \\
\hline \multicolumn{4}{|l|}{ Up-regulated } \\
\hline NM_020666 & CDC-like kinase 4 & CLK4 & 4.4 \\
\hline NM_017664 & Ankyrin repeat domain 10 & ANKRD10 & 2.9 \\
\hline NM_005520 & $\begin{array}{l}\text { Heterogeneous nuclear } \\
\text { ribonucleoprotein } \\
\mathrm{H} 1(\mathrm{H})\end{array}$ & HNRNPH1 & 2.9 \\
\hline NM_024941 & $\begin{array}{l}\text { Hypothetical protein } \\
\text { FLJ13611 }\end{array}$ & FLJ13611 & 2.7 \\
\hline NM_053024 & Profilin 2 & PFN2 & 2.7 \\
\hline NM_000598 & $\begin{array}{l}\text { Insulin-like growth factor } \\
\text { binding protein } 3\end{array}$ & $I G F B P 3$ & 2.6 \\
\hline NM_05278 & Glycoprotein M6B & $G P M 6 B$ & 2.6 \\
\hline NM_016730 & Folate receptor 1 (adult) & FOLR1 & 2.5 \\
\hline \multicolumn{4}{|l|}{ Down-regulated } \\
\hline NM_152545 & $\begin{array}{l}\text { RasGEF domain family, } \\
\text { member 1B }\end{array}$ & RasGEF $1 B$ & 5.9 \\
\hline NM_025217 & UL16 binding protein 2 & $U L B P 2$ & 4.6 \\
\hline NM_173171 & $\begin{array}{l}\text { Nuclear receptor } \\
\text { subfamily } 4 \text {, group A, }\end{array}$ & $N R 4 A 2$ & 4.1 \\
\hline NM_015014 & $\begin{array}{l}\text { RNA binding motif } \\
\text { protein } 34\end{array}$ & RBM34 & 4.1 \\
\hline NM_003745 & $\begin{array}{l}\text { Suppressor of cytokine } \\
\text { signalling } 1\end{array}$ & SOCS1 & 4.0 \\
\hline
\end{tabular}

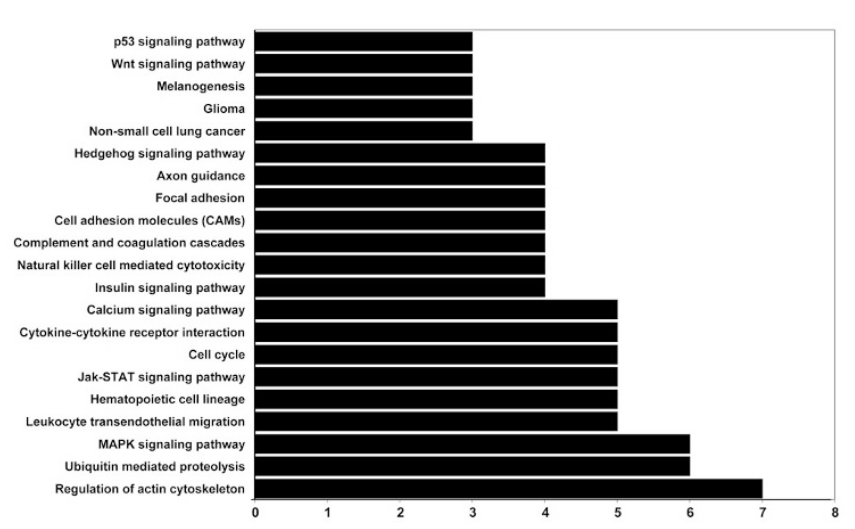

Figure 2. KEGG pathways where at least two gene members are dysregulated in patients with GAL with poor neurologic outcomes in comparison with favorable outcomes.

total $\mathrm{N}$-glycans released from pooled serum (adapted from reference 13). Figure 5 represents a typical whole serum $\mathrm{N}$-glycan profile for two treated patients with GAL (one with a good outcome and one with a poor neurologic outcome) in comparison with a pooled healthy control sample. Figure 6 outlines the nomenclature system used by the NIBRT DublinOxford Glycobiology Lab (14). The increased peak areas in the profiles for the patients with GAL are consistent with a lower percentage of galactose incorporation into biantennary serum glycoproteins in comparison with control. These $N$ glycan alterations were common across the GAL cohort and have generally been reported previously $(7,8)$.

For the severely affected patient (1), the total serum $\mathrm{N}$ glycan profile contains increased levels of G1 biantennary structures compared with control. However, this sample also showed differences in comparison to the other patient with 

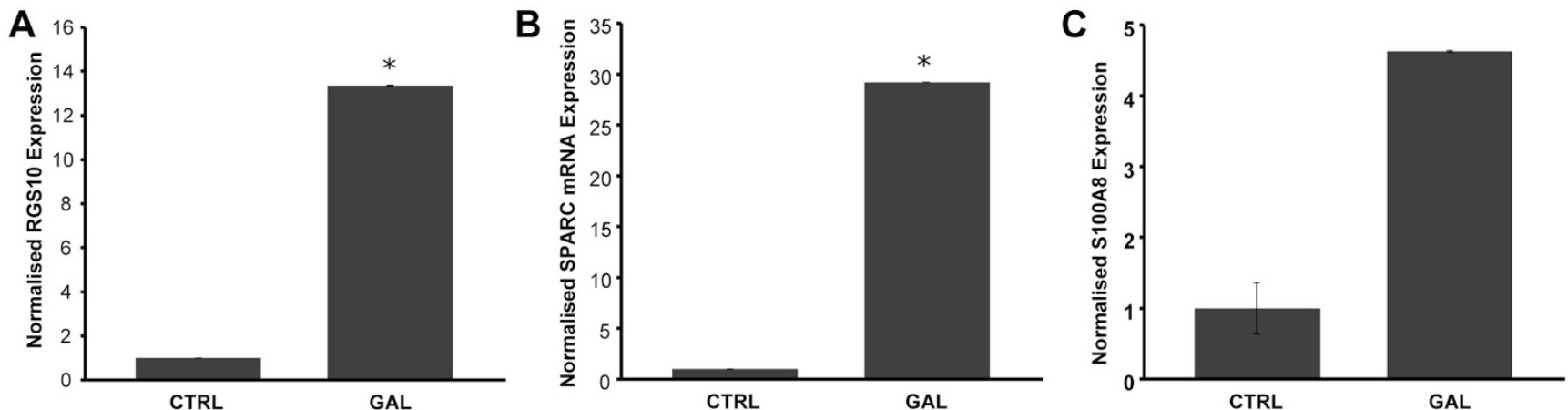

Figure 3. Verification of expression microarray data by quantitative real-time PCR. The graph represents the fold differences on expression level of the selected genes in RNA samples from the four index cases and three independent patients with GAL. ${ }^{*} p<0.05$. (A) RGS10, (B) SPARC, (C) S100A8.

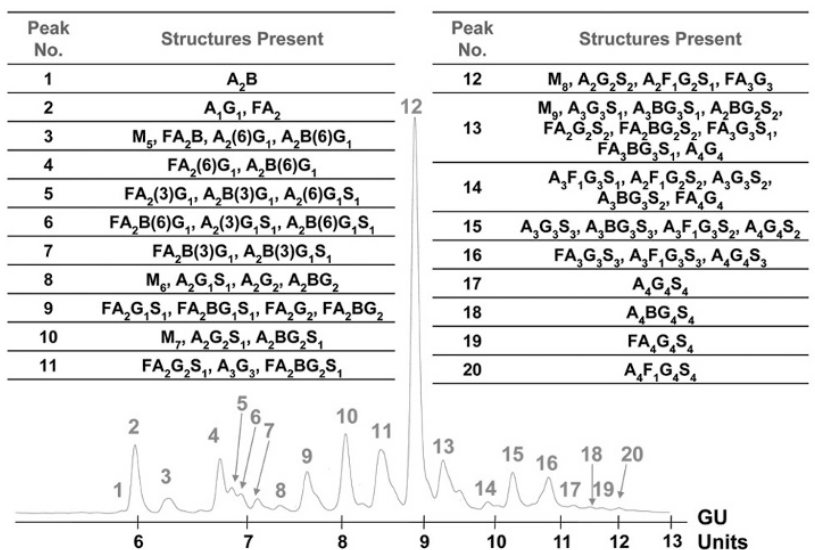

Figure 4. Represents the $N$-glycan profile of total serum glycoproteins released from a pooled serum sample. The glycan structures present in each of the pools are shown.

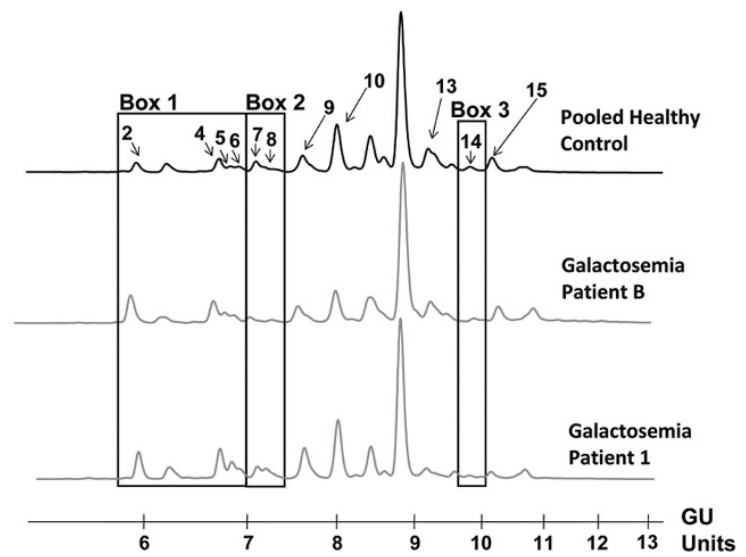

Figure 5. Illustrates a comparison of the total serum glycome from a healthy control, a representative patient with GAL and the patient with the most severe outcome (patient 1). Areas of particular interest are highlighted with boxes and arrows. Box 1 shows an increase in peaks 2, 4, 5, and 6 in both the patients with GAL relative to control. A decrease was shown in peaks 7 and 8 (Box 2) and peak 14 (Box 3) in the treated GAL profiles when compared with control. Patient 1 shows unique alterations in particular glycan pools such as increases in peaks 9 and 10 as well as a decrease in peaks 13 and 15 relative to both control and the overall GAL cohort.

GAL serum samples, including increased levels of A2G1, FA2G1 A2G2S1, and the bisects of some of these structures. This patient also has a decrease in the glycan pool containing

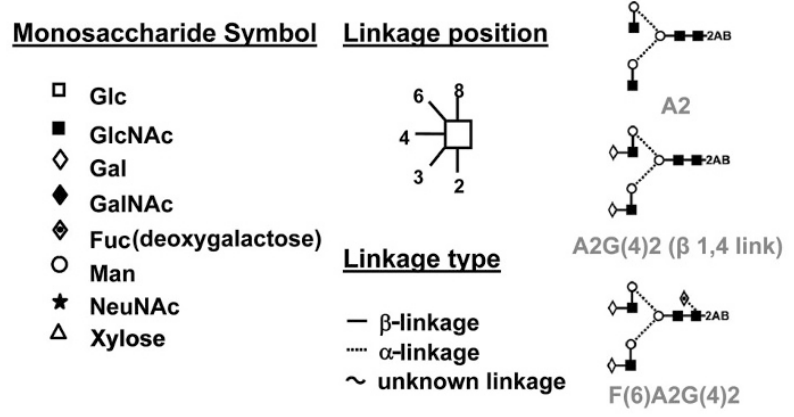

Figure 6. Outlines the nomenclature system used by the NIBRT DublinOxford Glycobiology Laboratory (see Ref.14 for structure designation).

large structures such as A3G3S3 (pool 15) relative to both the control samples and other GAL samples and also loss of core fucosylated A2G2S2 structures (pool 13).

We investigated the G0/G1 and (G0/G1)/G2 ratios between serum IgG purified from the GAL cohort and a pooled control sample (13). A representative trace for human serum $\operatorname{IgG}$ from a patient with GAL is shown in Figure 7. There was an increase in G0/G1 ratios between the GAL and control traces (Fig. 8), which was found to be significantly different (average fold increase of $1.71 \pm 0.34 \mathrm{SD} ; t$ test $p=0.02$ ). However, the $(\mathrm{G} 0 / \mathrm{G} 1) / \mathrm{G} 2$ ratio was not significantly different $(t$ test $p=$ $0.94)$ when the GAL cohort was compared with the pooled control.

Figure 7 indicates a number of pools in the $\operatorname{IgG}$ glycan profile containing both mono- and di-galactosylated structures. To allow for a more accurate measurement of the G0/G1 and $(\mathrm{G} 0 / \mathrm{G} 1) / \mathrm{G} 2$ ratios, exoglycosidase digestions were carried out on the purified IgG $N$-glycans using ABS and BKF to remove terminal sialic acid and core fucose from these samples. Figure 9 shows a representative ABS BKF digestion profile for a patient with GAL in comparison with a pooled control sample. Again, there is a significant increase in G0 containing peaks in the GAL set and a decrease in G2 peaks. The $\mathrm{G} 0 / \mathrm{G} 1$ and $(\mathrm{G} 0 / \mathrm{G} 1) / \mathrm{G} 2$ ratios from the $\operatorname{IgG} N$-glycan digestion products were then determined for the GAL and control cohorts (Fig. 10). The difference between the two groups was significant ( $t$ test $p=0.003$ and 0.004 , for G0/G1 and $\mathrm{G} 0 / \mathrm{G} 1 / \mathrm{G} 2$ ratios, respectively). Of note, patient $\mathrm{M}$, who has self-liberalized his diet, and also patient 1 were outliers 


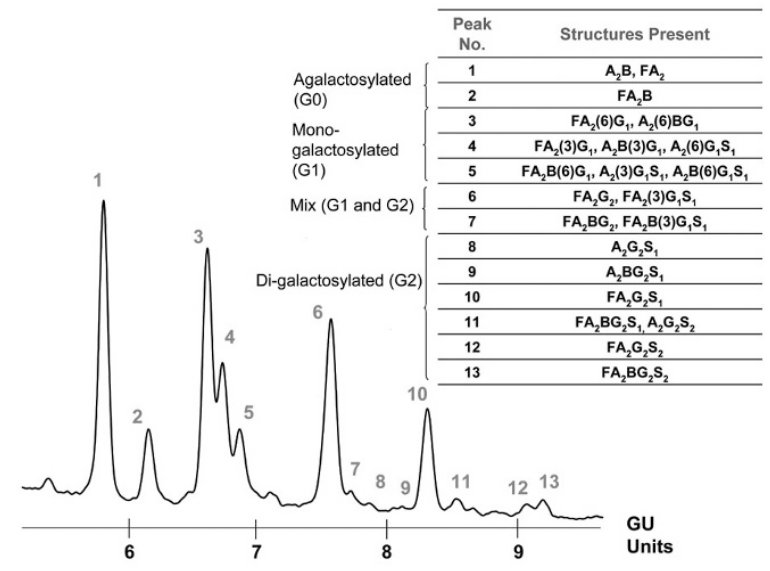

Figure 7. Representative chromatograph for human serum IgG glycans from a patient with GAL with the glycan structures listed for each designated pool. A number of pools in the undigested IgG profile contain both mono- and di-galactosylated structures.

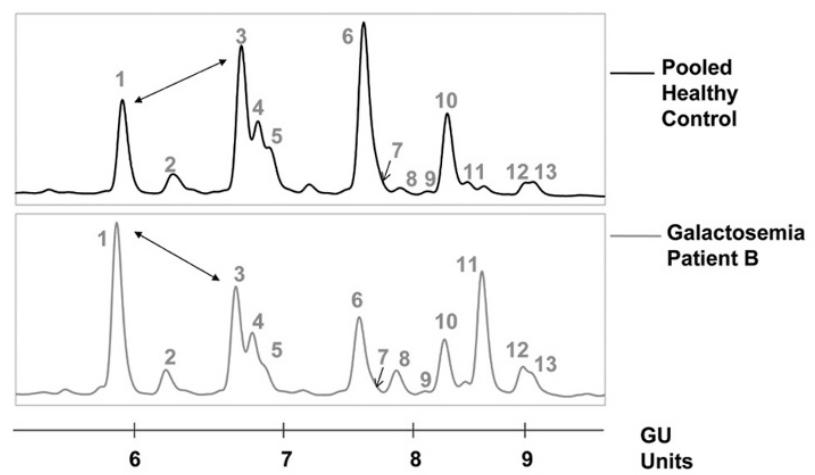

Figure 8. Representative chromatographs for undigested IgG-derived $\mathrm{N}$ glycans from the pooled control sample and a patient with GAL. The GAL sample demonstrates an increase in agalactosylated IgG $N$-glycans compared with control (indicated by arrows).

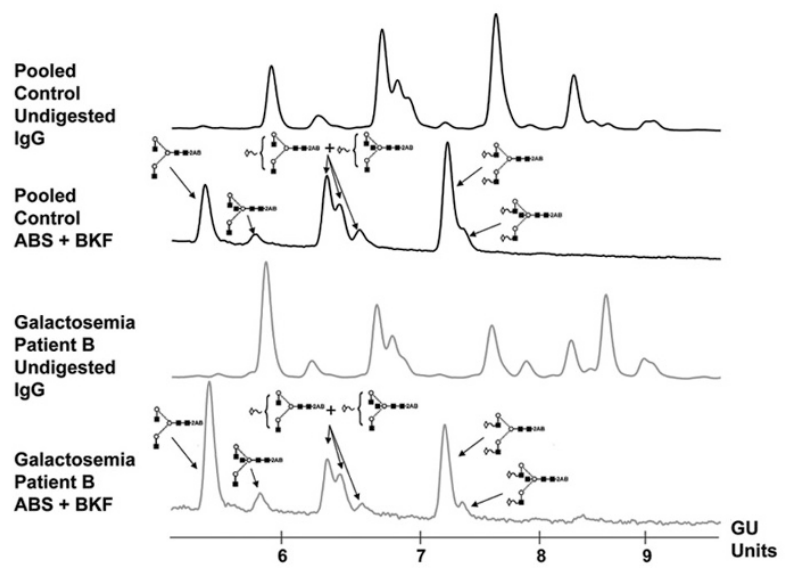

Figure 9. Representative ABS BKF digestion profile for a patient with GAL vs a pooled control sample. Again, there is an increase in G0 containing peaks in the GAL set and a decrease in G2 peaks.

with the lowest (G0/G1)/G2 ratio of the GAL set. This may indicate improved $\mathrm{IgG}$ galactosylation status in patient $\mathrm{M}$. However, this finding is somewhat paradoxical in the context of the more abnormal total serum glycan profile seen for patient 1 . The relatively low $(\mathrm{G} 0 / \mathrm{G} 1) / \mathrm{G} 2$ ratio found in patient

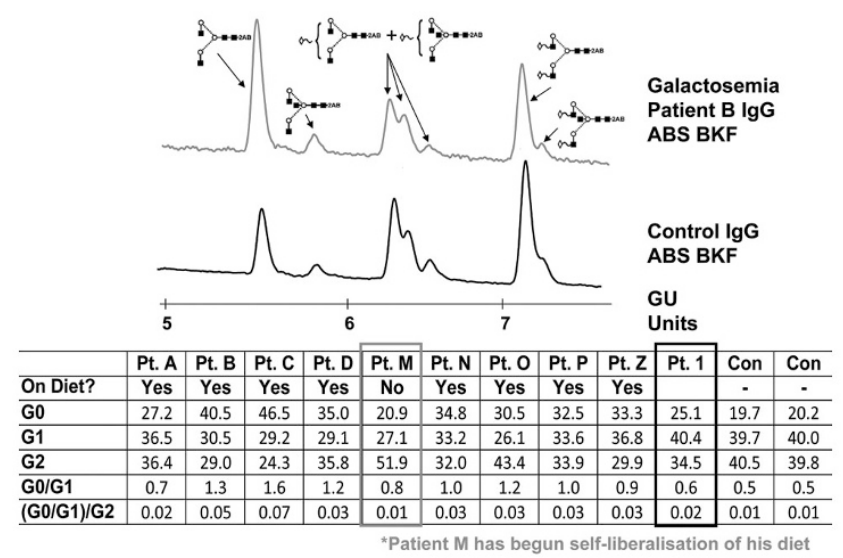

Figure 10. G0/G1 and (G0/G1)/G2 ratios from the $\operatorname{IgG} N$-glycan digestion products for the GAL and control samples.

1 may reflect the increased levels of biantennary G1 and G2 structures and concomitant decrease in large branched structures detected in the total serum profile relative to the other patients with GAL (Fig. 5).

\section{DISCUSSION}

In this study, we have demonstrated substantial differential gene expression in T lymphocytes in a small cohort of patients with GAL in comparison with controls and also have demonstrated significant differential gene expression between patients with GAL with satisfactory and poor neurologic outcomes. Our results indicate that GAL is associated with common and precise gene expression alterations affecting multiple metabolic pathways.

The array data that are currently presented represent the expression profiles of patients with GAL on a galactose restricted diet in $\mathrm{T}$ lymphocytes and do not represent the earlier life events or untreated GAL.

The process of glycosylation modulates interactions of receptors and ligands with themselves, coregulatory molecules and distinct membrane domains of intact cells, thus altering signal transduction. Variation in glycolipid function regulates the activation of various cell-surface growth factor receptors by mechanisms that also modulate ligand binding and receptor dimerization (15).

Comparing patients with GAL with normal controls, we have identified major systemic signaling pathway dysfunctioning in these patients, to include aberrations of the MAPK signaling pathway, regulation of the actin cytoskeleton, focal adhesion, and cytokine-cytokine receptor interaction. UPR is also substantially affected, for example USP 42 is 10 -fold up-regulated. Disturbed UPR is well recognized to have a significant role in many neurodegenerative diseases, (e.g. Alzheimer's disease, Parkinson's disease) $(16,17)$.

Figure 2 illustrates the comparative expression pattern between patients with GAL with favorable versus poor outcomes, indicating affected pathways to include MAPK signaling, regulation of actin cytoskeleton, the calcium signaling pathway, cell adhesion molecules in addition to the hematopoietic cell lineage, and the cell cycle. Table 2 illustrates the 
top 10 genes up-regulated in the total GAL group. Two regulators of $\mathrm{G}$ protein signaling were significantly upregulated in the total GAL group, RGS10 and RGS18 (159and 121-fold increased, respectively). The RGS family are known to negatively impair signaling pathways involving transmembrane receptors and $\mathrm{G}$ proteins including MAPK activation by mammalian G-protein-linked receptors $(18,19)$. In relation to the dysregulation of calcium signaling noted in our model, of note, RGS10 has been shown to be a key regulator of $\mathrm{Ca}^{2+}$ oscillations (20) and in an in vitro system over expression of RGS18 attenuated inositol phosphate production via G-alpha (q) in response to stimulating the angiotensin receptor (21). Slepak et al. (10) have noted altered calcium homeostasis in a GAL cell line when exposed to galactose with decreased free $\mathrm{Ca}^{2+}$ release from ER storage proposed to also operate through this pathway.

Expression of S100A8 (calprotectin subunit), a member of the S100 family of $\mathrm{Ca}^{2+}$ binding proteins accepted as a marker of inflammation, was markedly increased (122-fold). With S100A9, S100A8 is the major calcium and zinc binding protein of phagocytes and keratinocytes and has a critical factor in the innate immune response to infection (22).

Integrin beta 5 is 147 times up-regulated in patients with GAL in comparison with controls with also up-regulation of $I T G B 1$ and ITGBIBPI. Integrins are transmembrane receptors (glycoproteins) required for extracellular matrix and cell surface proteins, with functions including attachment and spreading, cytosolic signal cascades to promote cell migration, survival, proliferation, and differentiation (23). Integrin-mediated cell adhesion regulates gene expression via the activation of transcriptor factors, e.g. phosphatidylinositol 3-kinase, and may play a role in Wnt signaling pathways and expression of growth factor receptors (24).

$S D P R$, serum deprivation protein response (implicated in endocytosis, transcytosis, and cell signaling) was shown to be markedly up-regulated (25).

Epidermal growth factor $(E G F)$ was 27 -fold increased in the total patient group, whereas expression of EGFR a heavily glycosylated protein was decreased 4-fold. EGFR significantly affects MAP kinase signaling. These findings may relate to the growth retardation observed in some patients with GAL. EGFR expression has previously been shown to be decreased in a GALT-deficient cell line, proposed to result from a change in EGFR protein synthesis or turnover (10).

SPARC or osteonectin, a secreted $\mathrm{Ca}^{2+}$ binding glycoprotein important to bone calcification was up-regulated 138 -fold. SPARC null mice develop cataracts and severe osteopenia (26). Up-regulation of this gene may be secondary to the osteopenia noted in clinically treated patients with GAL (1).

Table 2 illustrates the top genes significantly downregulated in patients with GAL in comparison with controls. The gene most highly dysregulated (decreased 85 -fold) is Septin 4. Septins are a conserved group of GTP-binding and filament-forming proteins with diverse cellular functions including membrane dynamics, cytoskeleton reorganisation, polar determination, vesicle trafficking, exocytosis, and apoptosis and have been implicated in human neurodegenerative disease states such as Alzheimer's disease, Down syndrome, and in juvenile Parkinson's syndrome (27). Septins also play a significant role in innate host immunity. Microorganisms require interactions with the cytoskeleton, of possible relevance to the predisposition to Escherichia coli sepsis in untreated GAL neonates (28).

$D E F B 124$, defensin beta was also down-regulated 40-fold. Defensins are antimicrobial peptides active at cell surfaces with cytokine activity, important in innate host immunity (29).

Table 3 illustrates a number of genes with significant differences in expression between the severely affected and milder outcome patients.

Galactosylation is abnormal in patients with GAL and may play a role in the CNS manifestations of GAL by means of (1) impaired galactosylation of cerebrosides and glycoproteins in the brain (30) and (2) a reduction in UDP-glucose/galactose contents in GALT-deficient cells (9).

The $\mathrm{N}$-glycan analysis of whole serum from these patients highlighted a general increase in the levels of G0 and monogalactosylated G1 structures and a decrease in G2 and sialyated structures when compared with a control sample. Analysis of the serum $\operatorname{IgG~} N$-glycans from these patients indicated that levels of the $(\mathrm{G} 0 / \mathrm{G} 1) / \mathrm{G} 2$ ratio were higher in the GAL set and an individual patient who had already begun self-liberalization of his diet had a (G0/G1)/G2 ratio, which was within control levels with less pronounced glycan abnormalities compared with the other patients, consistent with improved glycosylation status. It should be noted that these differences may also correspond to altered levels of serum glycoproteins and that the site occupancy of $\operatorname{IgG}$ has not been investigated in this study.

In this study, we have used $\operatorname{IgG~N}$-glycosylation as a model for aberrations in glycosylation in patients with GAL. Our findings of increased levels of G0 structures associated with IgG potentially have a number of systemic implications. Alterations in the $\mathrm{IgG}$ associated $\mathrm{N}$-glycans such as decreased galactosylation leading to decreased sialylation can result in localized conformational changes which can in turn affect the interaction between IgG-Fc and other molecules. Terminal galactose residues on IgG are important for maintaining the half life and turnover rate of IgG by allowing it to bind efficiently to FcRn of relevance to autoimmune conditions such as rheumatoid arthritis and activation of the complement cascades and immune responses $(31,32)$.

Given the systemic implications of altered glycosylation of $\mathrm{IgG}$, it is likely that patients with GAL exhibit a number of altered glycoproteins, with distinct functional consequences, which could impact on a wide range of physiologic pathways. In support of this hypothesis, the whole serum $\mathrm{N}$-glycan profile from the GAL cohort may contain G0-, G1-derived structures from incompletely processed glycans from proteins other than $\operatorname{IgG}$ (Fig. 5 Box 1).

Our preliminary serum glycoprotein data are consistent with differing levels of abnormalities of glycoprotein processing combined with changes that suggest an assembly defect (see patient 1 in Fig. 5, the most severely affected patient on strict galactose restriction). It is noteworthy that the most "normal" profile in relation to the incorporation of galactose is in a patient on a liberalized diet. Although it is presumed that 
the main determinant of neurologic outcome related to glycoprotein and glycolipid synthesis is established during the first few years of life, it is interesting to note that there is a persistent abnormal profile in the most severely affected adult patient. From the total serum and IgG-derived $\mathrm{N}$-glycan profiles seen for this patient, it is not possible to identify a specific isolated $N$-glycan biosynthetic pathway defect because the contributing causes are expected to be multifactorial.

In conclusion, the microarray data presented illustrate cellular perturbations involving multiple signaling pathways and cascades as a possible consequence of systemic abnormal galactosylation of numerous cellular glycoproteins with possible abnormalities of protein glycan site occupancy, folding and survival, and the synthesis of glycolipids with incongruent genotype-phenotypes and outcomes in one pair of siblings, as we have described previously (4). We propose that the persistent abnormal glycosylation of serum glycoproteins observed in these treated patients with these microarray data gives an indication of the systemic malfunctioning and metabolic dyshomeostasis persisting in "treated" GAL, of a variable nature indicating that GAL does not function as a single gene disorder (33). Follow-up analyses will be required initially to determine whether any of the dysregulated pathways may be modified by relaxation of severe galactose restriction which could potentially improve galactose substrate for UDP$\mathrm{Gal}$ and for galactosyl ceramides in these patients.

The restriction of dietary galactose is clearly life saving in the neonatal period. However, further studies are warranted to investigate the influence of modifier genes and accessory salvage pathways of galactose metabolism and individualized galactose tolerance (34). Follow-up studies are also needed to determine how inappropriate glycosylation impacts glycoprotein functioning in both adults and children with this systemic disorder.

Acknowledgments. We thank Colm Carolan for his technical assistance and Olivia Walsh, RN for her assistance.

\section{REFERENCES}

1. The Online Metabolic and Molecular Bases of Inherited Disease 2008 Galactosemia Chapter 72. Available at: http://www.ommbid.com/OMMBID/ the_online_metabolic_and_molecular_bases_of_inherited_disease/b/abstract/ part7/ch72. Accessed 20 July 2009

2. Waggoner DD, Buist NR, Donnell GN 1990 Long-term prognosis in galactosemia: results of a survey of 350 cases. J Inherit Metab Dis 13:802-818

3. Schweitzer S, Shin Y, Jakobs C, Brodehl J 1993 Long-term outcome in 134 patients with galactosemia. Eur J Pediatr 152:36-43

4. Hughes J, Ryan S, Lambert D, Geoghegan O, Clark A, Rogers Y, Hendroff U, Monavari A, Twomey E, Treacy EP 2009 Outcomes of siblings with classical galactosemia. J Pediatr 154:721-726

5. Stibler H, von Dobeln U, Kristiansson B, Guthenberg C 1997 Carbohydrate-deficient transferrin in Galactosemia. Acta Paediatr 86:1377-1378

6. Prestoz LL, Couto AS, Shin YS, Petry KG 1997 Altered follicle stimulating hormone isoforms in female Galactosemia patients. Eur J Pediatr 156:116-120
7. Charlwood J, Clayton P, Keir G, Mian N, Winchester B 1998 Defective galactosylation of serum transferrin in galactosemia. Glycobiology 8:351-357

8. Sturiale L, Barone R, Fiumara A, Perez M, Zaffanello M, Sorge G, Pavone L, Tortorelli S, O'Brien JF, Jaeken J, Garozzo D 2005 Hypoglycosylation with increased fucosylation and branching of serum transferrin $\mathrm{N}$-glycans in untreated galactosemia. Glycobiology 15:1268-1276

9. Lai K, Langley SD, Khwaja FW, Schmitt EW, Elsas LJ 2003 GALT deficiency causes UDP-hexose deficit in human galactosemic cells. Glycobiology 13:285-294

10. Slepak TI, Tang M, Slepak VZ, Lai K 2007 Involvement of endoplasmic reticulum stress in a novel classic galactosemia model. Mol Genet Metab 92:78-87

11. Crushell E, Chuku J, Mayne PD, Blatny J, Treacy EP 2009 Negative screening tests in classic galactosaemia caused by S135L homozygozity. J Inherit Metab Dis 32:412-415

12. Huang da W, Sherman BT, Lempicki RA 2009 Systematic and integrative analysis of large gene lists using DAVID bioinformatics resources. Nat Protoc 4:44-57

13. Royle L, Campbell MP, Radcliffe CM, White DM, Harvey DJ, Abrahams JL, Kim YG, Henry GW, Shadick NA, Weinblatt ME, Lee DM, Rudd PM, Dwek RA 2008 HPLC-based analysis of serum N-glycans on a 96-well plate platform with dedicated database software. Anal Biochem 376:1-12

14. Harvey DJ, Merry AH, Royle L, Campbell C, Dwek RA, Rudd PM 2009 Proposal for a common set of symbols for drawing structural diagrams of $\mathrm{N}$ - and O-linked carbohydrates and related compounds. Proteomics 9:3796-3801

15. Ohtsubo K, Marth JD 2006 Glycosylation in cellular mechanisms of health and disease. Cell 126:855-867

16. Singhal S, Taylor MC, Baker RT 2008 Deubiquitylating enzymes and disease. BMC Biochem 9:S3

17. Zhang K, Kaufman RJ 2006 The unfolded protein response: a stress signalling pathway critical for health and disease. Neurology 66:S102-S109

18. Druey KM, Blumer KJ, Kang VH, Kehrl JH 1996 Inhibition of G-protein-mediated MAP kinase activation by a new mammalian gene family. Nature 379:742-746

19. Yang S, Chen W, Stashenko P, Li YP 2007 Specificity of RGS10A as a key component in the RANKL signaling mechanism for osteoclast differentiation. J Cell Sci 120:3362-3371

20. Yang S, Li YP 2007 RGS10-null mutation impairs osteoclast differentiation resulting from the loss of [Ca2+]i oscillation regulation. Genes Dev 21:1803-1816

21. Park IK, Klug CA, Li K, Jerabek L, Li L, Nanamori M, Neubig RR, Hood L, Weissman IL, Clarke MF 2001 Molecular cloning and characterization of a novel regulator of G-protein signalling from mouse hematopoietic stem cells. J Biol Chem 276:915-923

22. Rahimi F, Hsu K, Endoh Y, Geczy CL 2005 FGF-2, IL-1beta and TGF-beta regulate fibroblast expression of S100A8. FEBS J 272:2811-2827

23. Zhao Y, Sato Y, Isaji T, Fukuda T, Matsumoto A, Miyoshi E, Gu J, Taniguchi N 2008 Branched N-glycans regulate the biological functions of integrins and cadherins. FEBS J 275:1939-1948

24. Yoganathan TN, Costello P, Chen X, Jabali M, Yan J, Leung D, Zhang Z, Yee A, Dedhar S, Sanghera J 2000 Integrin-linked kinase (ILK): a "hot" therapeutic target. Biochem Pharmacol 60:1115-1119

25. Hansen CG, Bright NA, Howard G, Nichols BJ 2009 SDPR induces membrane curvature and functions in the formation of caveolae. Nat Cell Biol 11:807-814

26. Gilmour DT, Lyon GJ, Carlton MB, Sanes JR, Cunningham JM, Anderson JR, Hogan BL, Evans MJ, Colledge WH 1998 Mice deficient for the secreted glycoprotein SPARC/osteonectin/BM40 develop normally but show severe age-onset cataract formation and disruption of the lens. EMBO J 17:1860-1870

27. Hall PA, Russell SE 2004 The pathobiology of the septin gene family. J Pathol 204:489-505

28. Cossart P, Pizarro-Cerda J, Lecuit M 2003 Invasion of mammalian cells by Listeria monocytogenes: functional mimicry to subvert cellular functions. Trends Cell Biol $13: 23-31$

29. Ramasundara M, Leach ST, Lemberg DA, Day AS 2009 Defensins and inflammation: the role of defensins in inflammatory bowel disease. J Gastroenterol Hepatol 24:202-208

30. Lebea PJ, Pretorius PJ 2005 The molecular relationship between deficient UDPgalactose uridyl transferase (GALT) and ceramide galactosyltransferase (CGT) enzyme function: a possible cause for poor long-term prognosis in classic galactosemia. Med Hypotheses 65:1051-1057

31. Malhotra R, Wormald MR, Rudd PM, Fischer PB, Dwek RA, Sim RB 1995 Glycosylation changes of $\operatorname{IgG}$ associated with rheumatoid arthritis can activate complement via the mannose-binding protein. Nat Med 1:237-243

32. Alavi A, Axford JS 2008 Sweet and sour: the impact of sugars on disease. Rheumatology 47:760-770

33. Sriram G, Martinez JA, McCabe ER, Dipple KM 2005 Single-gene disorders: what role could moonlighting enzymes play? Am J Hum Genet 76:911-924

34. Lee PJ, Lilburn M, Wendel U, Schadewaldt P 2003 A woman with untreated galactosaemia. Lancet 362:446 